\title{
DEVELOPMENT OF NEW GENERATION “LIVE” FOODS WITH RATIONAL USE OF RAW MATERIALS FROM GEORGIAN RESOURSES
}

\author{
M. Silagadze ${ }^{1}$, E. Gamkrelidze ${ }^{2}$, S. Gachechiladze ${ }^{3}$, \\ M. Khurtsidze ${ }^{4}$, G. Pkhakadze ${ }^{5}$ \\ DOI: http://doi.org/10.15350/L_26/8/15
}

\begin{abstract}
Raw material with low glycemic index has been selected, such as - soybean, amaranth, lentil, topinambour, out of rich Georgian bioresources, their chemical composition, nutritional and energetic value has been studied. Investigation of germinating process of selected raw materials has done and optimal parameters are obtained. Georgian mineral waters have been used for the process optimization. New generation life products of vegetable milk and dietary bread have been produced using selected raw materials in complex with germinated grains, with high biological value, low caloricity, low glycemic index.
\end{abstract}

Keywords: vegetable milk; dietary bread; germinated grains; dietotherapy, functional food.

Negative dinamic of reproductive health in population, especially in young generation providing maintenance of healthy gene pool, has been noticed all over the world. Improper nutrition, stress, ecological and geopolitical cataclysms cause formation of plenty of free radicals which cause decreasing of immunity, developing of pathological processes and increasing of diseases caused by metabolic syndrome, such as, diabetes, dyslipidemia, obesity and others $[3,6]$. Nowdays the problem of complete and healthy nutrition is the most relevant and requires development and popularisation of new, functional, dietotherapic, nutritional products with high biological value, low caloricity and low glycemic index. This research is devoted to this issue.

The aim of the project is developing of "life" food of high biological value using local plant raw materials with perspectives of its use in dietotherapy of patients with deseases caused by metabolic syndrom.

${ }^{1}$ Maria Silagadze, full member of the Engineering Academy of Georgia, doctor of technical sciences, professor of Akaki Tsereteli University, Kutaisi, Georgia.

${ }^{2}$ Elene Gamkrelidze, candidate of chemical sciences, associated professor of Akaki Tsereteli University, Kutaisi, Georgia.

${ }^{3}$ Sofio Gachechiladze, Master of Biology, PHD student of Akaki Tsereteli State University, Kutaisi, Georgia.

${ }^{4}$ Manana Khurtsidze, PHD student of Akaki Tsereteli University, Kutaisi, Georgia.

5Giorgi Pkhakadze, 12 class student of Georgian - American school "Progress", Kutaisi, Georgia. 
During the working process standart and general organoleptic, physicochemical and biochemical methods of the research of plant raw materials and ready products have been used [1,2].

For developing of dietary products with low caloricity and glycemic index, on the first stage we have selected soybean, amaranth, lentil and topinambour out of rich Georgian bioresources by the following principle: soybean, lentil and topinambour - are low glycemic raw materials (their glycemic index is lower then 40). Soybeans are distinguished by low content of starch (3\%); topinambour bulbs are distinguished by high content of of biologically active substances. It contains complete proteins, like soybean, and carbohydrates in a form of inuline with the content of $80 \%$ of dry matter. Inuline is the only polysaccharide consisting 95\% fructose, which stimulates the synthesis of vitamins and activates protective mechanism of imunity.

Amaranth is considered to be a plant of XXI century, and its corn is called God's golden corn. Grains of amaranth have especial value, due to having a special substance- squalene, which has strong antioxidation ability participating in metabolism. Squalene is biological compound, natural unsaturated hydrocarbon. This hydrocarbon lack 12 hydrogen atoms for stable condition, that is why given unsaturated hydrocarbon traps these atoms from any available sources. Water is the most abundant source of hydrogen in organism, that's why squalene easily reacts with it, liberating oxygen and supplying organs and tissues with oxygen. With ingesting into the organism, squalene rejuvenates cells, it has an ability of increasing immunity of an organism in several times, providing its resistance against different diseases. It is cultivated in Georgia.

To prepare products with high biological value with balanced composition, we conducted directed modification of grains using of one of the most perspective and safe methods - enzymatic modification, which is based on activation of its endoenzymatic system of seeds itself which is happening during germination on humid environment $[1,4.5]$.

On the initial stage of the research we germinated cereals and leguminous seeds. First we selected them and inserted into water, held and took out floated dead seeds from the surface. Then rinsed them up several times and treated them for disinfection with diluted solution of potassium permanganate, then rinsed them once more and after that held them inside water for germination. In our work we use modified method of germination by Wigmore Ann. We placed seeds for soaking and swelling into the glass container for 6-8 hours and observed germination process during 5 days. According to the existing recommendations the length of the sprouts used for food mustn't exceed 2-5mm. (pic. 1).

Then we took patterns for analyses and determined general nutritional substances inside. Chemical composition, nutritional and energetic value of selected raw materials, also their variation during germination is given in table 1. 


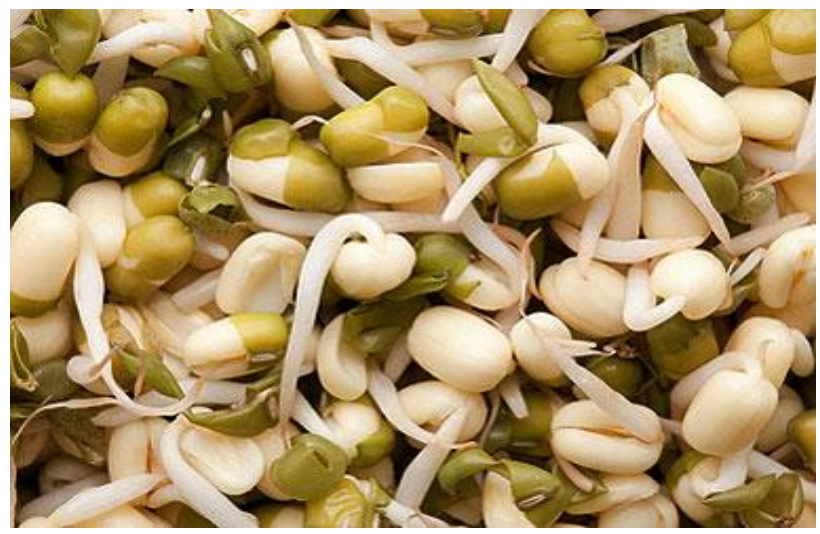

Pic. 1. Germinated soybean

Table 1

Variation of chemical composition in selected raw materials during germination of grains $(\mathrm{g} / 100 \mathrm{~g}$ product)

\begin{tabular}{|l|c|c|c|c|c|c|}
\hline \multirow{2}{*}{$\begin{array}{c}\text { Name of general } \\
\text { components }\end{array}$} & \multicolumn{3}{|c|}{ Before germination } & \multicolumn{3}{c|}{ After germination } \\
\cline { 2 - 7 } & soybean & lentil & Amaranth & soybean & lentil & Amaranth \\
\hline Water & 11,8 & 14,1 & 11,2 & 65,8 & 64,0 & 57,2 \\
\hline Proteins & 34,6 & 23,8 & 14,1 & 13,2 & 8,7 & 7,9 \\
\hline Lipids & 16,9 & 1,3 & 6,8 & 6,9 & 0,9 & 3,8 \\
\hline Carbohydrates & 16,7 & 45,5 & 56,2 & 8,8 & 21,2 & 26,7 \\
\hline Food fibers & 11,5 & 10,8 & 7,3 & 1,1 & 2,0 & 1,9 \\
\hline Ash & 4,8 & 3,2 & 3,1 & 3,4 & 2,1 & 2,0 \\
\hline $\begin{array}{l}\text { Energetic } \\
\text { value(ccal/100g) }\end{array}$ & 357,3 & 288,9 & 342,4 & 150,1 & 127,7 & 172,6 \\
\hline
\end{tabular}

By the experiments it is determined that after germination the amount of nutritional substances significantly decreased, caloricity is respectively decreased: soybean - by 59\%; amaranth - by $50 \%$; lentil - by $56 \%$.

During the process of germination we studied the influence of different factors (temperature, duration of soaking and germination, hydromodule, multiplicity of spraying) on the duration and energy of germination. Conducted experiments showed the optimal germinating conditions and modes: for soybean - 72 hours; for amaranth - 120-144 hours; for lentil - 60-72 hours.

On the next step of our work for the process optimization we used Georgian mineral waters "Borjomi" and "Nabeglavi" of average mineralization, also mineral water of Tskaltubo slightly containing radon, chlorine, hyrdocarbonate, sulfate (instead of tap water) which accelerates the process of germination and decreases the duration approximately by 1,5-3,0 hours. The process of germination also accelerated and duration of germination is decreased by 1,5 - 2,0 days. Analysis of vitamin $C$ showed that practically it lacked at primary raw material, only in amaranth a little amount of Vitamin $\mathrm{C}$ was recorded $-4,2 \mathrm{mg} \%$. After germination, in 48 hours it was: in amaranth $-55 \mathrm{mg} \%$; in soybean $-21 \mathrm{mg} \%$; in lentil $-29 \mathrm{mg} \%$. Increasing of vitamin C is especially no- 
ticed with use of mineral waters. The highest results were recorded using of mineral water from Tskaltubo (the amount of vitamin C in amaranth - 152mg\%; in lentil - 54mg\%; in soybean - 48mg\%).

In all experiments we used wheat grains as a control, as the most examined one.

At the last stage of the research we developed "live" products and dietary bread named "Our daily bread" using selected raw materials and germinated grains.

In laboratory conditions we prepared soybean milk and extraction "okara". Their production was happening the following order: we inserted sorted and washed soybean grains into glass container for soaking. The temperature of water was $20-25^{\circ} \mathrm{C}$, duration of soaking - 6 hours. To avoid specific taste of soybean we changed water 3-4 times during soaking. The ratio of grains and water is 1:3. At the end of the soaking grains increased in volume 2-2,4 times and the outer layer was flaked which is floated on the surface and could be removed by washing. After that we put grains into the blender, poured water with ratio 1:2 and started blending. Then water was added and continue blending. Water was used 5-6 times more then soybean for the whole process. Blended cereal was replaced into the pot for boiling. The process of boiling occured on low fire in approximately $15-20$ minutes. After boiling soybean milk was cooled to $50-60^{\circ} \mathrm{C}$ temperature and milk was separated from thick precipitation by sifting through the gauze. After finishing this procedure we prepared two products - soybean milk and soybean extract. 3 liters of soybean milk and 1,65kg soybean extract were produced from $1 \mathrm{~kg}$ of soybean. 5 liters of water were consumed on $1 \mathrm{~kg}$ soybean. Duration of storage of obtained products in refrigerators did not exceed 3 days. The chemical composition of soybean processing products was given on table 2 .

Table 2

The chemical composition of soybean processing products (g, on $100 \mathrm{~g}$ of the product)

\begin{tabular}{|c|c|c|c|}
\hline Name of compounds & Soybean grain & Soybean milk & Soybean extract \\
\hline water & 13,1 & 90,3 & 77,9 \\
\hline proteins & 33,6 & 3,1 & 3,7 \\
\hline lipids & 16,3 & 1,9 & 1,9 \\
\hline carbohydrates & 17,8 & 3,0 & 11,8 \\
\hline Food fibers & 14,0 & 0,7 & 3,8 \\
\hline ash & 4,8 & 0,6 & 0,8 \\
\hline Energetic value, kcal & 364 & 41,6 & 79,1 \\
\hline
\end{tabular}

"Live" products were prepared from soybean milk and soybean extract by adding of germinated grains. Raw or dry germinated grains were added to the soybean milk and then they were blended together. Germinetad grains of soyben, amaranth or lentil 5-8\% amount can be added as live additing. To prepare protein-lipid paste amaranth oil can be added to soybean extract 3-5\% amount. After intense mixing of ingredients flavoring materials were added to them. Also we prepared dietary bread named Our daily bread. 
The following raw materials and functional ingredients are used for preparing bread: I quality wheat flour, pressed yeast, salt, vegetable oil, soybean milk or lactic acid product, soybean extract, germinated grains, amaranth flour, mashed topinambour, water and spices.

First raw materials must be prepared - heating of water, preparing of yeast emulsion salt and water solution, soybean milk and extract, preparing of lactic acid products from soybean milk, germinating of grains.

Dough preparation is provided in two phases - sourbread (opara) and dough. First soybean milk and lactic acid products, yeast emulsion, flour are put into the emulsifier where all inserted components must be blended during 5-8 minutes. During this process flour is added by portions. At the end of the blending the mass filled with oxygen is placed into the bowl for fermentation. This process lasts 90-120 minutes. After that salty water, soybean extract, vegetable oil, germinated grains, amaranth flour, mashed topinambour, spices, flour, water are added into the risen dough and mixing of dough is done on low speed. This process lasts 15-20 minutes, after which rising of dough is happened on optimal mode, on 3,5-4,5 $\mathrm{C}^{0}$ before increasing acidity. After that molding of dough must be done (cutting, shaping, twisting), next making the dough rising and cooking at last. Cooking must be done in the convection oven first in the vaporised area and then on the temperature $220-230^{\circ} \mathrm{C}$ during $35-45$ minutes. After cooling formed bread is packed up into polyethylene film.

Profilogram of organoleptic characteristics of processed assortment is given on the figure:

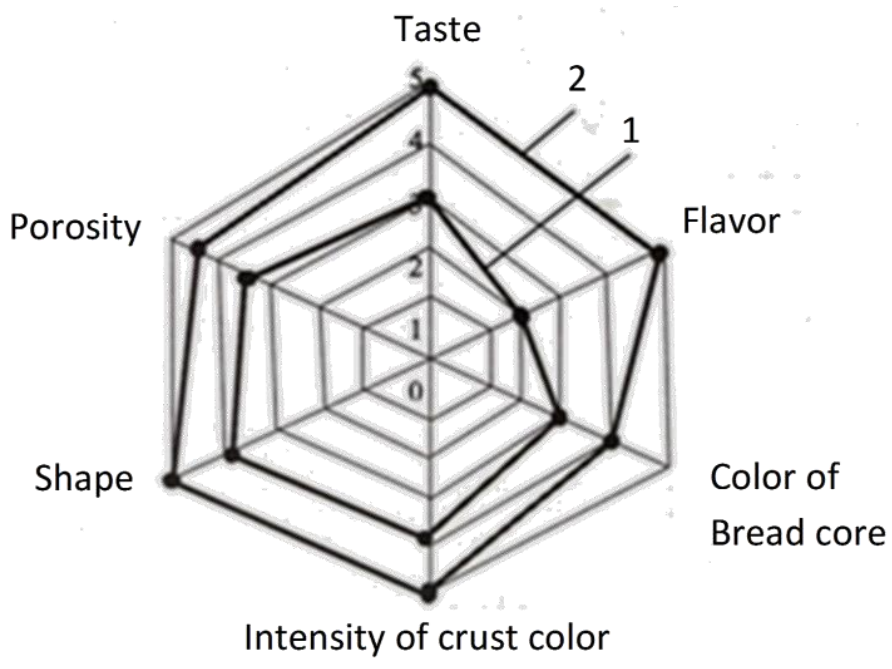

Fig. 1. Profilogram of organoleptic indicators of the bread 1 - control - wheat bread from I quality flour 2 - produced dietary bread 


\section{Conclusion}

Scientifically determined and experimentaly processed "live" nutritional products of high biological value, low caloricity, low glycemic index on the base of the results taken from complex researches used for dietotherapy of patients with metabolic syndrom:

Vegetable cereals and leguminous raw materials are selected from rich bioresources of Georgia: soybean, amaranth, lentil, topinambour. Their chemical composition are determined and nutritional and energetic values are calculated; Research of germinating process of selected raw materials is done to increase their biological value. Variation dynamics of basic components are studied by the effect of different technological factors on the process of germination. Optimal parameters of germination are determined. Variation dynamic of vitamin $-\mathrm{C}$ is also learnt. It is determined that energetic value of grains is significantly decreased and amount of vitamin $-\mathrm{C}$ is considerably increased;

Georgian mineral waters are approved for optimization of germinating process. The highest results are recorded using mineral water of Tskaltubo slightly containing radon, chlorine, hyrdocarbonate, sulfate;

New generation vegetable milk products and dietary bread of high biological value, low caloricity, low glycemic index are produced with complex use of selected raw materials and germinated grains. Their energetic and nutritional values are calculated.

\section{References}

[1] Vigmor E.P Sprouts - Life food // Translate from English-SPB.-ID,,Ves”. 2001. p.208

[2] Podkopaeva Z.P., Fedotova A.A., Kuzina M.B. Germinated seeds of leguminous crops as prospective tends in technology of products of functional purpose//Vestnik.-Oriol.GIET.-2013. N1 (23).-pp.141-143.

[3] Kudriasheva A.A. Secrets of good health and active long life//A.A. Kudriasheva. M. Pishepromizdat. 2000. p.320

[4] Ermakov A.I. Methods of biochemical research of plants//Edited by Ermakov A.I. Ed.2. Rewrote and completed-Leningrad. Kolos. 1972. p.456

[5] Tutelian V.A Nutrition and health // Zh. Food industry. M. N5. 2004. p.5-6

[6] Skalnii A.V., Rudakov I.A Bioelements in medicine. M.:"Oniks 21century". Mir. 2004.p. 272 